AperTO - Archivio Istituzionale Open Access dell'Università di Torino

Directed: Ortho-metalation-nucleophilic acyl substitution strategies in deep eutectic solvents: The organolithium base dictates the chemoselectivity

This is a pre print version of the following article:

Original Citation:

Availability:

This version is available http://hdl.handle.net/2318/1707022

since 2021-03-10T12:19:54Z

Published version:

DOI:10.1039/c9cc03927a

Terms of use:

Open Access

Anyone can freely access the full text of works made available as "Open Access". Works made available under a Creative Commons license can be used according to the terms and conditions of said license. Use of all other works requires consent of the right holder (author or publisher) if not exempted from copyright protection by the applicable law. 


\title{
Directed ortho-Metalation-Nucleophilic Acyl Substitution Strategies in Deep Eutectic Solvents: The Organolithium Base Dictates the Chemoselectivity
}

Simone Ghinato, ${ }^{\mathrm{a}}$ Giuseppe Dilauro, ${ }^{\mathrm{b}}$ Filippo Maria Perna,${ }^{\mathrm{b}}$ Vito Capriati, ${ }^{\mathrm{b}, *}$ Marco Blangetti ${ }^{\mathrm{a}, *}$ and Cristina $\operatorname{Prandi}^{\mathrm{a}, *}$

${ }^{a}$ Dipartimento di Chimica, Università di Torino, via P. Giuria 7, 10127 Torino, Italy

${ }^{b}$ Dipartimento di Farmacia, Scienze del Farmaco, Università di Bari “A. Moro”, Consorzio C.I.N.M.P.I.S.

Via E. Orabona 4, I-70125 Bari (Italy)

Corresponding authors: Cristina Prandi, Marco Blangetti, Vito Capriati

Phone: +39-0116707643; +39-0116708033.

E-mail address: cristina.prandi@unito.it; marco.blangetti@unito.it, vito.capriati@uniba.it

\begin{abstract}
We report a general and rapid chemoselective functionalization of aromatic carboxylic acid amides with organolithium reagents by using Deep Eutectic Solvents (DESs) as environmentally friendly reaction media. Directed ortho metalation or nucleophilic acyl substitution processes can be selectively privileged at room temperature in air depending on the nature of the organolithium species. One-pot sequential ortholithiation/Suzuki-Miyaura cross-couplings have also been demonstrated for the first time in DESs. This opens up new synthetic opportunities in terms of efficiency and environmental sustainability.
\end{abstract}

Amides are excellent starting materials and intermediates for organic synthesis due to their easy availability and preparation, ${ }^{[1]}$ and versatile reactivity. ${ }^{[2]}$ The reaction of highly reactive s-block organometallic compounds with aromatic amides may lead to two results: directed ortho metalation (DoM) with aromatic $\mathrm{C}-\mathrm{H}$ functionalisation or nucleophilic acyl substitution $\left(\mathrm{S}_{\mathrm{N}} \mathrm{Ac}\right)$. Among direct metalation groups (DMGs), the pioneering work of Beak and co-workers in this area established that tertiary benzamides can be more effective 
than any other non-amide units in directing lithiation to an adjacent position provided that a bulky base (e.g. sec-BuLi) jointly with $N, N, N^{\prime}, N^{\prime}$-tetramethylethylenediamine (TMEDA) as the complexing agent are used at $-78^{\circ} \mathrm{C}$ in THF. The choice of reactants and metalation conditions is, indeed, crucial to avoid the competing nucleophilic substitution. ${ }^{[3]}$ On the other hand, the direct, selective acylation of the above organometallics is notoriously complicated by the over-addition of these reagents to the product ketones leading to the formation of tertiary alcohols. One general solution to favor acyl-transfer reactions is to improve the stability of the transient tetrahedral intermediate, thereby avoiding its collapse to the ketone during the reaction. ${ }^{[4]}$ In this context, successful strategies have included the use of (a) Weinreb amides with chelating functional groups, ${ }^{[5]}$ (b) $\mathrm{N}$-acylpyrroles, ${ }^{[6]}$ (c) chemoselective methods based on an activation/addition sequence on secondary amides, ${ }^{[7]}$ and (d) the use of $N$-acylazetidines as twisted amides ${ }^{[8]}$ The use of non-conventional solvents as a method of controlling the $\mathrm{S}_{\mathrm{N}} \mathrm{Ac}$ process is under-developed. Increasing environmental awareness has pressured companies to become more proactive in addressing public concerns related to the development of cleaner methods of chemical production and to drive the field of synthetic chemistry toward more green practices. ${ }^{[9]}$ The use of renewable feedstocks, which is one of the 12 principles of Green Chemistry, is seen by many as an important strategy towards sustainable development. ${ }^{[10]}$ The ability to telescope multiple bond-forming events in a one-pot process is another strategy to reduce the amount of solvent used in a synthetic sequence, and minimize waste production. From these perspectives, Deep Eutectic Solvents (DESs, easily obtainable by mixing and gently warming two or three safe and inexpensive components that can undergo self-association) represent a novel and promising class of unconventional, green solvents, that can potentially replace the classical petroleum-derived volatile organic compounds (VOCs). Common mixtures derive from a quaternary ammonium salts (e.g., choline chloride, $\mathrm{ChCl}$ ) and a neutral hydrogen-bond donor (HBD) [e.g., glycerol (Gly), urea, natural carboxylic acids, amino acids], and thus they are exceptionally high biodegradable with toxicities that are non-existent or very low. ${ }^{[11]}$ Recent independent investigations by Hevia, García-Álvarez and Capriati on the reactivity of Grignard and organolithium reagents in protic, biorenewable media and under hydrous conditions (often considered the natural foes of these organometallic reagents) have established a step change in the way that the chemistry of these commodity reagents can be carried out using environmentally friendly conditions: alkylation/arylation of ketones, imines and nitriles, at room temperature (RT), under air, and in DESs or glycerol or water, have provided tertiary alcohols, amines, ketones and carbinamines in very good 
yields and competitively with protonolysis (Scheme 1a,b). ${ }^{[12]}$ A THF-directed ortho-lithiation and lateral lithiation in ChCl-based eutectic mixtures in the presence of cyclopentyl methyl ether (CPME) has also successfully granted access, under open air conditions and at RT, to functionalized diaryltetrahydrofurans and primary alcohols, respectively. ${ }^{[13]}$

\section{Previous work:}

Hevia, Garcia-Alvarez, Capriati (2014-2016) $)^{12 a, d}$

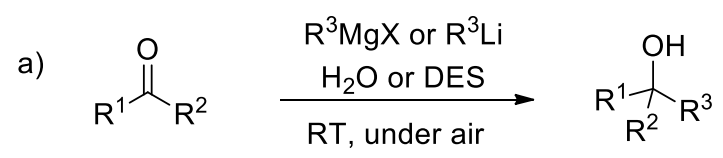

Hevia, Garcia-Alvarez, Capriati (2017-2018) 2 b-c,f

b)

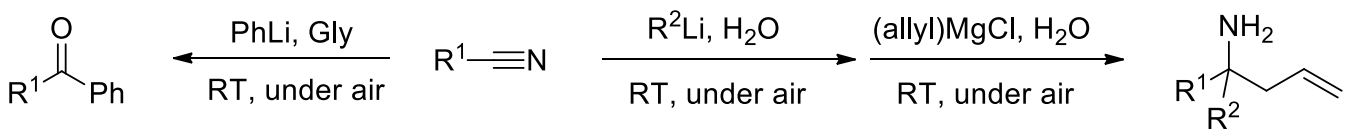

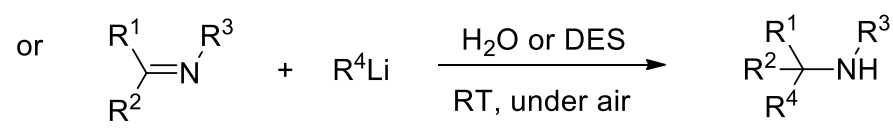

This work:

c)
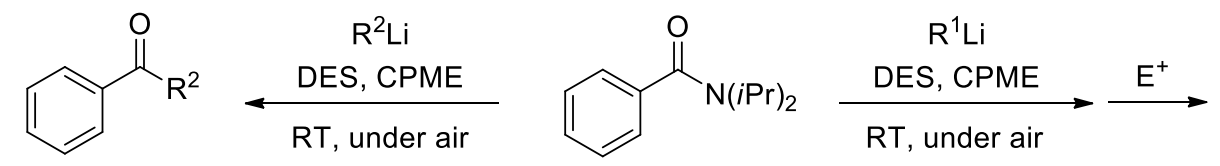<smiles>O=C(Nc1ccccc1)c1ccccc1F</smiles>

Scheme 1. (a) Addition reactions of organometallics to carbonyl compounds in DESs or water; (b) Addition reactions of organometallics to imines and nitriles in DESs or water; (c) ortho-Lithiation and nucleophilic acyl substitution of a benzamide derivative in ethereal/eutectic mixtures.

Building on our long-standing interest in polar organometallic chemistry ${ }^{[14]}$ and recent findings in using water or DESs as privileged reaction media with organometallics, ${ }^{[12 \mathrm{~d}-\mathrm{f}, 13,15]}$ we now report a systematic study on the usefulness of DESs as sustainable media for promoting chemoselective DoM or $\mathrm{S}_{\mathrm{N}} \mathrm{Ac}$ processes starting from the same carboxylic acid amide. Notable features of our report include: (a) divergent synthetic pathways according to the nature of the lithiating reagent, (b) direct ortho-functionalization of benzamides and ketones synthesis in DES, (c) ability to telescope ortho-metalation/Suzuki-Miyaura transformations in a one-pot process to synthesize valuable "building blocks", d) absence of VOCs. 
We began our investigation using $N, N$-diisopropylbenzamide 1a as a model substrate since it is known to be completely resistant nucleophilic attack by alkyllithiums at the amide carbonyl, and to be easily orthofunctionalized in a total chemoselective fashion with $t$-BuLi, sec-BuLi or even $n$-BuLi as the lithiating agents. $^{[3 \mathrm{a}, 3 \mathrm{~b}, 16]}$ In a preliminary experiment, amide $\mathbf{1 a}(0.2 \mathrm{mmol})$ was suspended in a prototypical choline chloride $(\mathrm{ChCl}) /$ glycerol (Gly) eutectic mixture $(1: 2 \mathrm{~mol} / \mathrm{mol})$ and then reacted at $\mathrm{RT}$ in air with a commercial 1.7 M pentane solution of $t$-BuLi (2 equiv) under continuous stirring. Quenching the reaction mixture with MeI ( 5 equiv) after $2 \mathrm{~s}$, however, led to quantitative recovery of $\mathbf{1 a}$ after work up (Table 1, entry 1 ). When $t$ BuLi (2 equiv) was added in one portion to a suspension of $\mathbf{1 a}(0.2 \mathrm{mmol})$ (previously solubilized in a small amount of CPME $(0.2 \mathrm{~mL}), 1 \mathrm{M})^{[17]}$ in the above eutectic mixture, under air at RT and with vigorous stirring to generate an emulsion, and then quenched after $2 \mathrm{~s}$ with MeI (5 equiv), the ortho-methylated adduct 2a was this time isolated in $70 \%$ yield as the sole product (Table 1 , entry 2 ). No traces of any nucleophilic addition product were detected by ${ }^{1} \mathrm{H}$ NMR and GC-MS analyses of the crude reaction mixture when amide 1a was treated with $t$-BuLi either in the presence or in the absence of electrophile. Under these conditions, ${ }^{2} \mathrm{H}$ NMR analysis of the deuterated product 1a-D, resulting from the treatment of $\mathbf{1 a}$ with $t$-BuLi followed by quench with $\mathrm{CD}_{3} \mathrm{OD}$, disclosed a selective incorporation of deuterium at the ortho position in up to $86 \%$ ( $83 \%$ yield) (see Supporting Information) (Table 1, entry 3).

Table 1. Metalation reaction of $N, N$-diisopropylbenzamide 1a using $t$-BuLi under different conditions. ${ }^{[a]}$

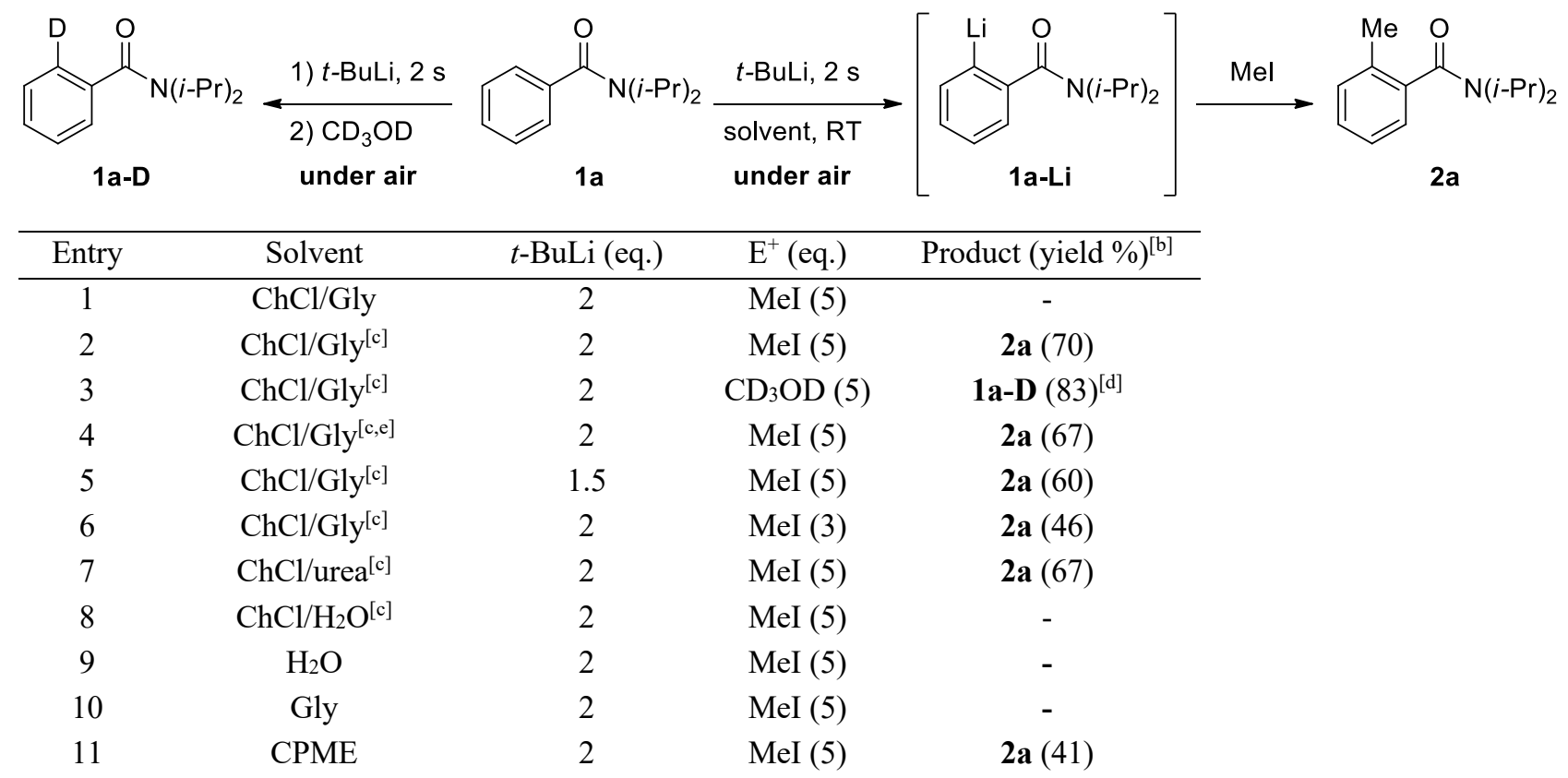

[a] Reaction conditions: $1.0 \mathrm{~g}$ DES per $0.2 \mathrm{mmol}$ of 1a; DES: $\mathrm{ChCl} / \mathrm{Gly}\left(1: 2 \mathrm{~mol} \mathrm{~mol}^{-1}\right)$; $\mathrm{ChCl} /$ urea $(1: 2$ mol mol $\left.{ }^{-1}\right) ; \mathrm{ChCl} / \mathrm{H}_{2} \mathrm{O}\left(1: 2 \mathrm{~mol} \mathrm{~mol}{ }^{-1}\right)$. [b] Determined by ${ }^{1} \mathrm{H} \mathrm{NMR}$ using $\mathrm{CH}_{3} \mathrm{NO}_{2}$ as the internal standard. [c] CPME: $0.2 \mathrm{~mL}$. [d] $86 \% \mathrm{D}$ incorporation. [e] $\mathrm{T}=0{ }^{\circ} \mathrm{C}$. 
No significant changes were observed when the reaction was run at $0{ }^{\circ} \mathrm{C}$ (Table 1, entry 4). Efforts were made to further improve the conversion of the starting material. Lowering the organolithium from 2 to 1.5 equiv and the electrophile from 5 to 3 equiv led to a decrease of conversion (Table 1, entries 5,6). Next, we evaluated the half-life of 1a-Li in the above protic medium. Experiments were designed to show the reaction progress over time with reaction samples quenched with MeI at different times following treatment of the substrate 1a with $t$-BuLi. The first-order plot obtained indicated an estimated half-life for 1a-Li of $6.26 \mathrm{~s}$ (see Supporting Information). Switching $\mathrm{ChCl} /$ urea $(1: 2 \mathrm{~mol} / \mathrm{mol})$ for $\mathrm{ChCl} / \mathrm{Gly}$ led to similar results (Table 1, entry 7$)$, whereas the use of water as HBD as well as the replacement of the eutectic mixture with water or glycerol was ineffective (Table 1, entries 8-10). When using pure CPME as the solvent, ortho-functionalized product 2a was obtained, albeit in $41 \%$ yield (Table 1, entry 11 ).

The scope and limitation of this transformation was then evaluated for a series of electrophiles and different benzamide derivatives. Electrophiles such as benzaldehyde, DMF and various halogenating, sulfurylating and silylating agents reacted smoothly with anion $\mathbf{1 a - L i}$, thereby providing the expected ortho-functionalized

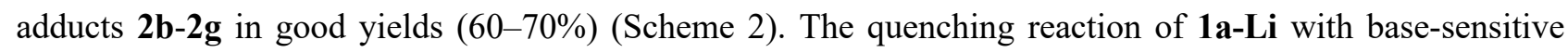
functional groups (e.g. esters) and $\mathrm{CO}_{2}$ was less favourable and furnished the aromatic ketone $\mathbf{2 h}$ and the carboxylic acid derivative $\mathbf{2 i}$ in $23-34 \%$ yield (Scheme 2). Amide derivatives bearing electron-withdrawing or electron-donating groups on the aromatic ring were also tested. Metalation-deuteration of $\mathbf{1 b}-\mathbf{d}$ always took place proximal to the amide moiety (up to $95 \% \mathrm{D}$ ), (a) both at the ortho and at the ortho' position in the case of $\mathbf{1 b}$ (and not in competition with lateral lithiation) and (b) leaving the chloride unreacted in the case of $\mathbf{1 d}$, and thus available for further functionalisation (Scheme 2). Formylation of ortho-lithiated $\mathbf{1 b}$ with DMF afforded products $\mathbf{2} \mathbf{j}, \mathbf{k}$ in $\mathbf{7 3 \%}$ yield, however as an inseparable 1:1 mixture of regioisomers. On the other hand, bromination and formylation of ortho-lithiated $\mathbf{1 c - L i}$ and $\mathbf{1 d - L i}$ regioselectively led to products $\mathbf{2 1 , \mathbf { m }}$ in $61-83 \%$ yield. Interestingly, indole derivative 1e showed $90 \%$ deuterium incorporation at the 3-position when sequentially treated with $t$-BuLi and $\mathrm{CD}_{3} \mathrm{OD}$ (see ${ }^{2} \mathrm{H}$ NMR analysis, Supporting Information), and provided product 2n in 68\% yield when anion 1e-Li was quenched with $\mathrm{PhCHO}$. 


$$
\begin{aligned}
& \text { 1a: } N, N \text {-diisopropylbenzamide } \\
& \text { 1b: } N, N \text {-diisopropyl-3-methylbenzamide } \\
& \text { 1c: } N, N \text {-diisopropyl-4-methoxybenzamide } \\
& \text { 1d: 4-chloro- } N, N \text {-diisopropylbenzamide } \\
& \text { 1e: } N, N \text {-diisopropyl-1-methyl-1H-indole-2-carboxamide }
\end{aligned}
$$

Scheme 2. Scope of the ortho-lithiation reaction of $N, N$-diisopropylbenzamides 1a-e in CPME/DES (ChCl/Gly 1:2 $\left.\mathrm{mol} \mathrm{mol}^{-1}\right)$ mixture. Reaction conditions: 1a-e $(0.2 \mathrm{mmol}), t$-BuLi (1.7 $\mathrm{M}$ in pentane, $\left.0.4 \mathrm{mmol}\right), \mathrm{CPME}$ $(0.2 \mathrm{~mL})$, DES (1.0 g), electrophile (5 equiv unless otherwise stated). The yields reported are for products isolated after flash column chromatography. [a] The amount of the electrophile can be reduced to 1.2 equiv without any loss in terms of yield. [b] $\mathrm{I}_{2}$ was added as a $2 \mathrm{M}$ solution in 2-MeTHF. [c] $\mathrm{CO}_{2}$ was bubbled for 15 s. [d] Overall percentage yield and overall percentage deuteration (ratio $\mathbf{1 b}-\mathbf{D}: \mathbf{1 b}$-D $=1: 1$ ). [e] Overall percentage yield (ratio $\mathbf{2} \mathbf{j}: \mathbf{2} \mathbf{k}=1: 1$ ).

We then explored the reactivity of our model substrate $\mathbf{1 a}$ toward other organolithium reagents. When amide 1a was treated in a CPME/DES (ChCl/Gly 1:2) mixture at $\mathrm{RT}$ under air with sec-BuLi either in the presence or in the absence of MeI as the electrophile, only the starting material was recovered. Alternatively, using $n$ BuLi (2 equiv) as the nucleophilic reagent, only a mixture of valerophenone 3a and alcohol $\mathbf{4 a}$ in a 5:1 molar ratio ( $85 \%$ conversion) was detected in the crude reaction mixture after $20 \mathrm{~s}$ (Table 2, entry 1). When amide 1a was treated with $n$-BuLi (2 equiv) in a CPME/DES (ChCl/Gly 1:2) mixture and quenched after $2 \mathrm{~s}$ using MeI as the electrophile, ketone 3a and alcohol 4a were formed in the same 5:1 ratio as the sole products. Such a remarkable chemoselectivity toward the $S_{N} A c$ pathway was similarly observed upon replacing the Gly 
component of the DES with urea (Table 2, entry 2), whereas the use of water or lactic acid (LA) as the HBD led to a lower or no conversion (Table 2, entries 3,4). These reproducible results point toward a somewhat stabilising effect of certain eutectic mixtures upon the transient tetrahedral intermediate. The conversion could be increased up to $90 \%$ and the ketone to alcohol ratio improved up to $6: 1$ by running the acyl substitution at $0{ }^{\circ} \mathrm{C}$ (Table 2, entry 5). It was proved that both the stirring speed and the synergistic use of CPME/DES are crucial for the outcome of this transformation. Indeed, when the organolithium addition was performed under gentle and not vigorous stirring so as to minimize the area of interface, the conversion dropped to $60 \%$ (Table S3, Supporting Information). Similarly, the use of pure solvents such as CPME, Gly and water, showed a significant decrease in terms of conversion and chemoselectivity (Table S3, Supporting Information). Under these conditions, the use of other aliphatic and aromatic, commercially available organolithium reagents, ranging from MeLi to $n$-HexLi and $\mathrm{PhLi}$ led to the desired ketone derivatives $\mathbf{3 b}-\mathbf{d}$ in satisfactory yields (6070\%) (Table 2, entries 6-8).

Table 2. Nucleophilic acyl substitution reactions promoted by organolithiums on $N, N-$ diisopropylbenzamides 1a-e in different eutectic mixtures.

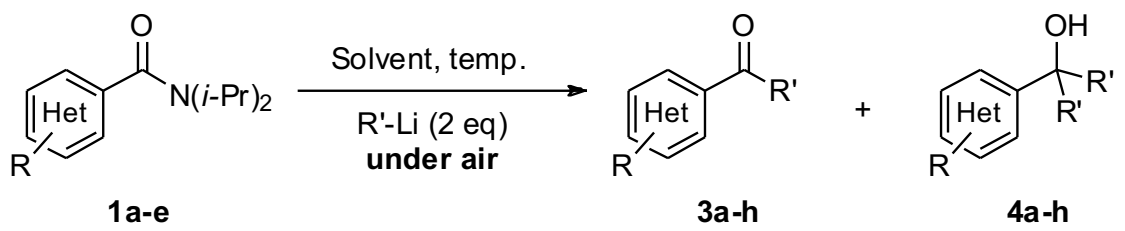

\begin{tabular}{cccccccc}
\hline Entry & Solvent ${ }^{[a]}$ & Substrate & $\mathrm{R}^{\prime}$ & $\mathrm{T}\left({ }^{\circ} \mathrm{C}\right)$ & \% Conv ${ }^{[\mathrm{b}, \mathrm{c}]}$ & Product & $\mathbf{3 : 4}$ ratio $^{[\mathrm{b}]}$ \\
\hline 1 & $\mathrm{ChCl} / \mathrm{Gly}$ & $\mathbf{1 a}$ & $n-\mathrm{Bu}$ & 25 & 85 & $\mathbf{3 a}$ & $5: 1$ \\
2 & $\mathrm{ChCl} / \mathrm{urea}$ & $\mathbf{1 a}$ & $n-\mathrm{Bu}$ & 25 & 80 & $\mathbf{3 a}$ & $5: 1$ \\
3 & $\mathrm{ChCl} / \mathrm{H}_{2} \mathrm{O}$ & $\mathbf{1 a}$ & $n-\mathrm{Bu}$ & 25 & 50 & $\mathbf{3 a}$ & $2: 1$ \\
4 & $\mathrm{ChCl} / \mathrm{LA}$ & $\mathbf{1 a}$ & $n-\mathrm{Bu}$ & 25 & - & $\mathbf{3 a}$ & - \\
5 & $\mathrm{ChCl} / \mathrm{Gly}$ & $\mathbf{1 a}$ & $n-\mathrm{Bu}$ & 0 & $90(65)$ & $\mathbf{3 a}$ & $6: 1$ \\
6 & $\mathrm{ChCl} / \mathrm{Gly}$ & $\mathbf{1 a}$ & $\mathrm{Me} \mathrm{e}^{[\mathrm{d}]}$ & 0 & $70(60)$ & $\mathbf{3 b}$ & $5: 1$ \\
7 & $\mathrm{ChCl} / \mathrm{Gly}$ & $\mathbf{1 a}$ & $n-\mathrm{Hex}$ & 0 & $87(69)$ & $\mathbf{3 c}$ & $5: 1$ \\
8 & $\mathrm{ChCl} / \mathrm{Gly}$ & $\mathbf{1 a}$ & $\mathrm{Ph}^{[\mathrm{e}]}$ & 0 & $89(70)$ & $\mathbf{3 d}$ & $6: 1$ \\
9 & $\mathrm{ChCl} / \mathrm{Gly}$ & $\mathbf{1 b}$ & $n-\mathrm{Bu}$ & 0 & $70(50)$ & $\mathbf{3 e}$ & $6: 1$ \\
10 & $\mathrm{ChCl} / \mathrm{Gly}$ & $\mathbf{1 c}$ & $n-\mathrm{Bu}$ & 0 & $78(56)$ & $\mathbf{3 f}$ & $4: 1$ \\
11 & $\mathrm{ChCl} / \mathrm{Gly}$ & $\mathbf{1 d}$ & $n-\mathrm{Bu}$ & 0 & $74(50)$ & $\mathbf{3 g}$ & $5: 1$ \\
12 & $\mathrm{ChCl} / \mathrm{Gly}$ & $\mathbf{1 e}$ & $n-\mathrm{Bu}$ & 0 & $90(60)$ & $\mathbf{3 h}$ & $7: 1$ \\
\hline
\end{tabular}

[a] Conditions: 1a-e $(0.2 \mathrm{mmol})$, CPME (0.2 mL), DES (1.0 g). DES: ChCl/Gly (1:2 mol mol $\left.{ }^{-1}\right)$; ChCl/urea $\left(1: 2 \mathrm{~mol} \mathrm{~mol}^{-1}\right)$; $\mathrm{ChCl} / \mathrm{H}_{2} \mathrm{O}\left(1: 2 \mathrm{~mol} \mathrm{~mol}^{-1}\right)$; $\mathrm{ChCl} / \mathrm{LA}\left(1: 2 \mathrm{~mol} \mathrm{~mol}^{-1}\right)$. Reaction time $20 \mathrm{~s}$ unless otherwise stated. Commercially available solutions of $n-\mathrm{BuLi}$ (2.5 $\mathrm{M}$ in hexanes), $\mathrm{PhLi}\left(1.8 \mathrm{M}\right.$ in $\left.\mathrm{Bu}_{2} \mathrm{O}\right), n-\mathrm{HexLi}$ (2.3 $\mathrm{M}$ in hexanes), and $\mathrm{MeLi}\left(1.6 \mathrm{M}\right.$ in $\mathrm{Et}_{2} \mathrm{O}$ ) were used ( 2 equiv). [b] Conversion and ratios were determined by GC analysis and/or ${ }^{1} \mathrm{H}$ NMR spectroscopy. [c] In brackets, isolated yield of ketone 3 after column chromatography on silica gel. [d] Reaction time: $60 \mathrm{~s}$. [e] Reaction time: $30 \mathrm{~s}$. 
The design of telescoped, one-pot processes involving multiple stoichiometric/catalytic events, such as those set up by assembling main group-mediated organic transformations and transition-metal-catalysed reactions, are attractive methodologies in the toolbox of synthetic chemistry for their intrinsic practical and economical advantages (e.g., minimisation of chemical waste, significant save of time and energy, and circumvention of purification phases) ${ }^{[19]}$ We recently found out that the environmentally responsible eutectic mixture $\mathrm{ChCl} / \mathrm{Gly}$ (1:2) was an effective reaction medium for performing ligand-free, chemoselective Suzuki-Miyaura (SM) couplings that proceeded in air and under generally mild conditions. ${ }^{[18]}$ Thus, we targeted telescoped DoMSM approaches for the preparation of more functionalized amides based on a preliminary, regioselective ortholithiation/iodination of amide 1a followed by an in situ Pd-catalysed SM reaction in the above-described eutectic mixture using different borates/boronic acids as nucleophilic partners. To this end, amide 1a was first treated with $t$ - $\mathrm{BuLi}$ in the $\mathrm{ChCl} / \mathrm{Gly} / \mathrm{CPME}$ mixture and then quenched after $2 \mathrm{~s}$ with a stoichiometric amount of iodine (1.2 equiv). ${ }^{[19]}$ The resulting ortho-iodo derivative $2 \mathbf{e}$ was finally subjected to a SM coupling reaction with phenylboronic acid (5a) or styryl potassium trifluoroborate (5b) or 2-thienylboronic acid pinacol ester (5c), by using $10 \mathrm{~mol} \%$ of $\mathrm{Pd}(\mathrm{OAc})_{2}$ as the catalyst and in the absence of any additional ligand, thereby affording valuable ortho-functionalized styryl or (hetero)aryl derivatives 6a-c in yields of up to $45 \%$ after two steps in one pot (Scheme 3).

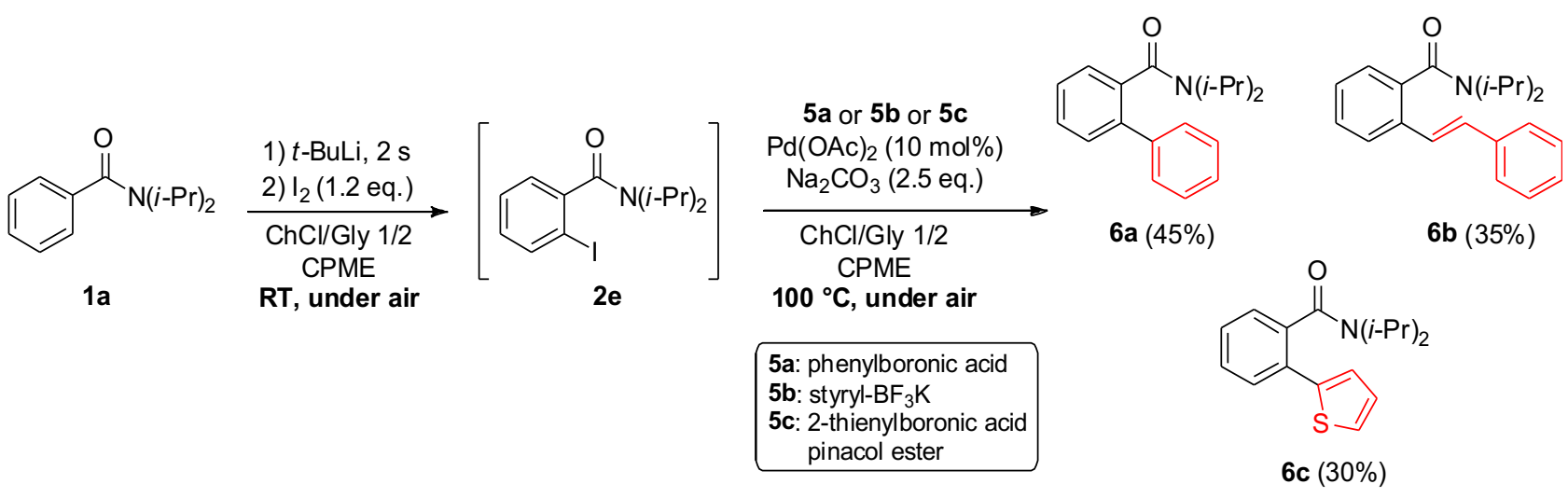

Scheme 3. Telescoped DoM/Suzuki-Miyaura arylation/vinylation of amide 1a in a ChCl/Gly/CPME mixture.

In summary, directed ortho metalation or nucleophilic acyl substitution processes, en route to functionalized amides and ketones, can be conveniently and regioselectively carried out starting from the same aromatic carboxylic acid amide using environmentally friendly eutectic mixtures (working under air, at RT or $0{ }^{\circ} \mathrm{C}$ ) 
depending on the nature of the organolithium reagent. The use of $t$-BuLi led to ortho-lithiation processes, while the use of less sterically encumbered organolithium reagents led to $S_{N} A c$ reactions. The low levels of tertiary alcohol by-products suggests that the DES plays a prominent role in stabilizing the tetrahedral intermediates. In addition, we have demonstrated the possibility of performing one-pot, telescoped ortho-lithiation/Pdcatalysed Suzuki-Miyaura coupling reactions in DES mixtures, which are of great value in terms of efficiency and environmental sustainability. Further extensions of this work are currently underway in our laboratories and results will be reported in due course.

\section{Acknowledgements}

This work was financially supported by MIUR (Italian Ministery of University and Research), by CRT (Cassa di Risparmio di Torino) foundation, by the University of Bari, and the Interuniversity Consortium C.I.N.M.P.I.S.

The authors are particularly grateful to Chris McErlean for fruitful and helpful discussion during his staying in Turin as Visiting Professor.

\section{Conflict of interest}

The authors declare no conflict of interest.

Keywords: deep eutectic solvents; directed ortho-metalation; nucleophilic addition; organolithium reagents; green chemistry.

\section{References}

[1] a) V. R. Pattabiraman, J. W. Bode, Nature 2011, 480, 471; b) C. L. Allen, J. M. J. Williams, Chem. Soc. Rev. 2011, 40, 3405-3415. 
[2] a) P. W. Tan, J. Seayad, D. J. Dixon, Angew. Chem. Int. Ed. 2016, 55, 13436-13440; b) K. L. White, M. Movassaghi, J. Am. Chem. Soc. 2016, 138, 11383-11389.

[3] a) P. Beak, R. A. Brown, J. Org. Chem. 1982, 47, 34-46; b) P. Beak, V. Snieckus, Acc. Chem. Res. 1982, 15, 306-312; c) P. Beak, A. Tse, J. Haawkins, C.-W. Chen, S. Mills, Tetrahedron 1983, 39, 1983-1989; d) V. Snieckus, Chem. Rev. 1990, 90, 879-933; e) J. Clayden, Organolithiums: Selectivity for Synthesis, , Pergamon, Oxford, 2002; f) G. A. El-Hiti, K. Smith, A. S. Hegazy, M. B. Alshammari, A. M. Masmali, Arkivoc 2015, iv, 19-47; g) F. R. Leroux, J. Mortier, in Directed Metalation of Arenes with Organolithiums, Lithium Amides, and Superbases, in Arene Chemistry: Reaction Mechanisms and Methods for Aromatic Compounds (Ed.: J. Mortier), John Wiley \& Sons, 2016, p. 749; h) S. Florio, A. Salomone, Synthesis 2016, 48, 1993-2008.

[4] a) M. Adler, S. Adler, G. Boche, J. Phys. Org. Chem. 2005, 18, 193-209; b) M. Szostak, L. Yao, J. Aubé, J. Am. Chem. Soc. 2010, 132, 2078-2084.

[5] a) S. Nahm, S. M. Weinreb, Tetrahedron Lett. 1981, 22, 3815-3818; b) M. J. Zacuto, R. F. Dunn, M. Figus, J. Org. Chem. 2014, 79, 8917-8925; c) V. Pace, L. Castoldi, W. Holzer, J. Org. Chem. 2013, 78, 7764-7770.

[6] a) D. A. Evans, G. Borg, K. A. Scheidt, Angew. Chem. Int. Ed. 2002, 41, 3188-3191; b) S. T. Heller, J. N. Newton, T. Fu, R. Sarpong, Angew. Chem. Int. Ed. 2015, 54, 9839-9843.

[7] W. S. Bechara, G. Pelletier, A. B. Charette, Nature Chem. 2012, 4, 228.

[8] C. Liu, M. Achtenhagen, M. Szostak, Org. Lett. 2016, 18, 2375-2378.

[9] a) B. M. Trost, Science 1991, 254, 1471; b) B. M. Trost, M. U. Frederiksen, M. T. Rudd, Angew. Chem. Int. Ed. 2005, 44, 6630-6666; c) R. A. Sheldon, Green Chem. 2007, 9, 1273-1283.

[10] a) P. T. Anastas, J. C. Warner, Green Chemistry: Theory and Practice, Oxford University Press, Oxford, 1998; b) A. S. Matlack, Introduction to Green Chemistry, Marcel Dekker, New York, 2001; c) M. Poliakoff, J. M. Fitzpatrick, T. R. Farren, P. T. Anastas, Science 2002, 297, 807; d) M. Lancaster, Green Chemistry: An Introductory Text, RSC Publishing, Cambridge, 2002.

[11] a) C. Ruß, B. König, Green Chem. 2012, 14, 2969-2982; b) Q. Zhang, K. De Oliveira Vigier, S. Royer, F. Jérôme, Chem. Soc. Rev. 2012, 41, 7108-7146; c) P. Liu, J.-W. Hao, L.-P. Mo, Z.-H. Zhang, RSC Adv. 2015, 5, 48675-48704; d) M. Francisco, A. van den Bruinhorst, C. Kroon Maaike, Angew. Chem. Int. Ed. 2013, 52, 3074-3085; e) E. L. Smith, A. P. Abbott, K. S. Ryder, Chem. Rev. 2014, 114, 1106011082; f) A. Alonso Diego, A. Baeza, R. Chinchilla, G. Guillena, M. Pastor Isidro, J. Ramón Diego, Eur. J. Org. Chem. 2016, 2016, 612-632.

[12] a) C. Vidal, J. Garcia-Alvarez, A. Hernan-Gomez, A. R. Kennedy, E. Hevia, Angew. Chem., Int. Ed. 2014, 53, 5969-5973; b) C. Vidal, J. Garcia-Alvarez, A. Hernan-Gomez, A. R. Kennedy, E. Hevia, Angew. Chem. Int. Ed. 2016, 55, 16145-16148; c) M. J. Rodriguez-Alvarez, J. Garcia-Alvarez, M. Uzelac, M. Fairley, C. T. O'Hara, E. Hevia, Chem. Eur. J. 2018, 24, 1720-1725; d) L. Cicco, S.

Sblendorio, R. Mansueto, F. M. Perna, A. Salomone, S. Florio, V. Capriati, Chem. Sci. 2016, 7, 11921199; e) L. Cicco, M. J. Rodríguez-Álvarez, F. M. Perna, J. García-Álvarez, V. Capriati, Green Chem. 2017, 19, 3069-3077; f) G. Dilauro, M. Dell'Aera, P. Vitale, V. Capriati, F. M. Perna, Angew. Chem. Int. Ed. 2017, 56, 10200-10203; g) J. García-Álvarez, E. Hevia, V. Capriati, Eur. J. Org. Chem. 2015, 2015, 6779-6799; h) J. García-Álvarez, E. Hevia, V. Capriati, Chem. Eur. J. 2018, 10.1002/chem.201802873.

[13] a) V. Mallardo, R. Rizzi, F. C. Sassone, R. Mansueto, F. M. Perna, A. Salomone, V. Capriati, Chem. Commun. 2014, 50, 8655-8658; b) F. C. Sassone, F. M. Perna, A. Salomone, S. Florio, V. Capriati, Chem. Commun. 2015, 51, 9459-9462.

[14] a) S. Parisotto, P. Boggio, C. Prandi, P. Venturello, A. Deagostino, Tetrahedron Lett. 2015, 56, 57915794; b) M. Blangetti, H. Mueller-Bunz, D. F. O'Shea, Chem. Commun. (Cambridge, U. K.) 2013, 49, 6125-6127; c) M. Blangetti, P. Fleming, D. F. O'Shea, J. Org. Chem. 2012, 77, 2870-2877; d) A. Deagostino, C. Prandi, S. Tabasso, P. Venturello, Curr. Org. Chem. 2011, 15, 2390-2412; e) M. Blangetti, P. Fleming, D. F. O'Shea, Beilstein J. Org. Chem. 2011, 7, 1249-1254, No. 1145; f) M. Blangetti, A. Deagostino, C. Prandi, S. Tabasso, P. Venturello, Org. Lett. 2009, 11, 3914-3917; g) M. Blangetti, A. Deagostino, C. Prandi, C. Zavattaro, P. Venturello, Chem. Commun. (Cambridge, U. K.) 2008, 1689-1691; h) A. Deagostino, C. Prandi, C. Zavattaro, P. Venturello, Eur. J. Org. Chem. 2006, 2463-2483. 
[15] G. Dilauro, A. Francesca Quivelli, P. Vitale, V. Capriati, F. M. Perna, Angew. Chem. Int. Ed. 2019, 58, 1799-1802.

[16] a) P. Beak, R. A. Brown, J. Org. Chem. 1977, 42, 1823-1824; b) P. Bowles, J. Clayden, M. Helliwell, C. McCarthy, M. Tomkinson, N. Westlund, J. Chem. Soc., Perkin Trans. 1 1997, 2607-2616.

[17] Lowering the amount of CPME as an additive led to a significant decrease in terms of conversion and ratio, and the $1 \mathrm{M}$ concentration turned out to be optimal. See Supporting Information for details.

[18] G. Dilauro, S. M. García, D. Tagarelli, P. Vitale, F. M. Perna, V. Capriati, ChemSusChem 2018, 11, 3495-3501.

[19] The use of less than 5 eq. of iodine was mandatory in order to avoid the undesired iodination of boron derivative. 


\section{Graphical abstract}

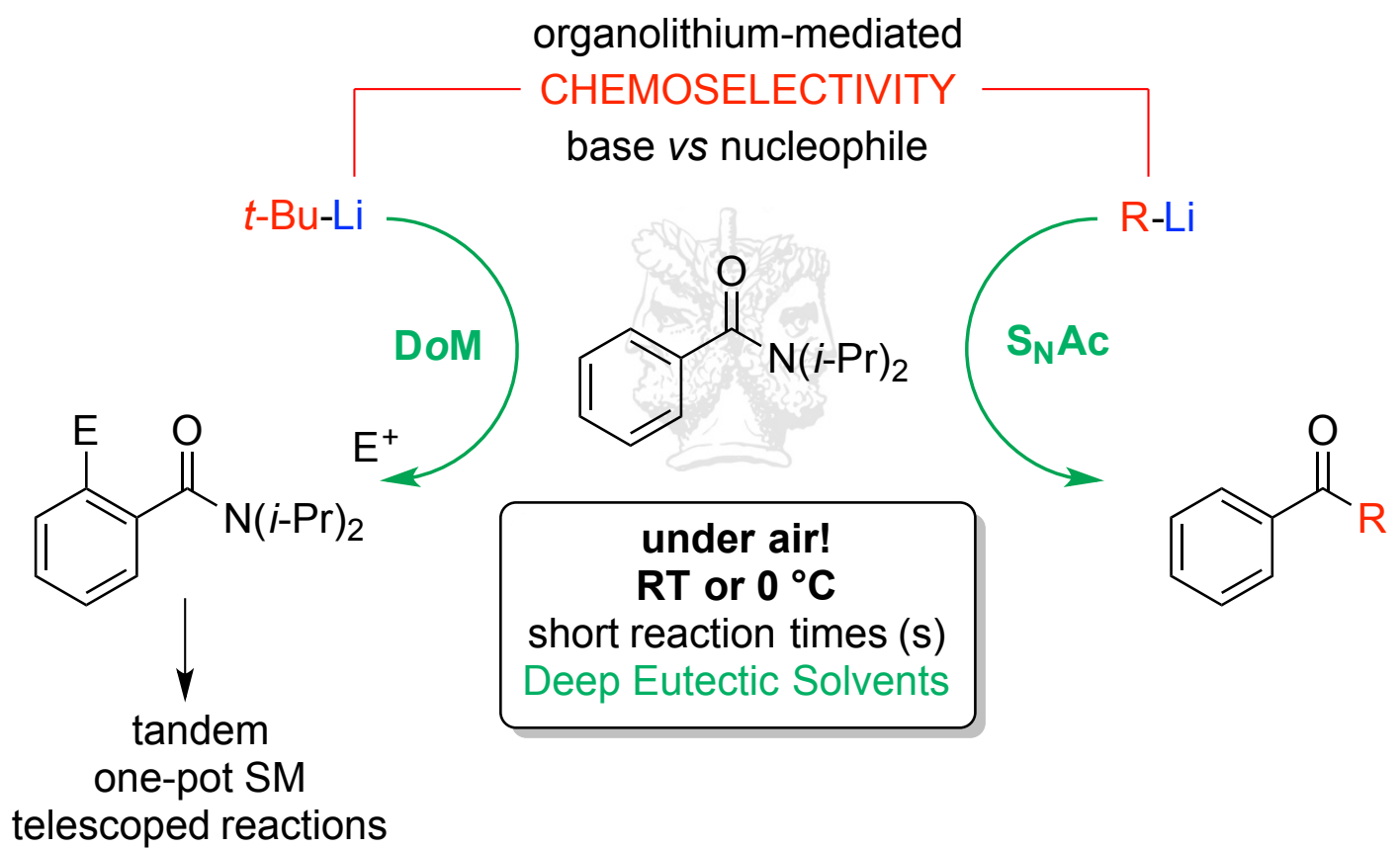

Janus-faced reactivity of carboxylic acid amides in Deep Eutectic Solvents (DESs) with organolithium reagents! Highly chemoselective and fast directed ortho metalation (DoM) or nucleophilic acyl substitution $\left(\mathrm{S}_{\mathrm{N}} \mathrm{Ac}\right)$ processes proceed smoothly in DESs, at room temperature or $0{ }^{\circ} \mathrm{C}$ and under air, depending on the nature of the organolithium reagent. 
